\title{
Only XL: The Assertoric Asymmetry of Exponibles
}

\author{
Laurence R. Horn \\ Yale University
}

\section{Exponibles and the Unpacking of only}

For the late medievals (cf. Ashworth 1972), an exponibilium or exponible proposition is an apparently simplex proposition that must be expounded (unpacked) into a formula involving the combination-typically via a simple conjunction - of two or more simpler propositions; derivatively, exponibilia also refers to those terms whose semantic analysis requires such an unpacking, e.g. the equivalents for only, every...but, begin, cease, insofar as. Even affirmative universals qualify as exponibles on the classical (Aristotelian) view, given the existential import of such statements: Every pleasure is good unpacks into There is no pleasure that is not good and There is pleasure. For our purposes, the key exponible is the converse of the universal, the exclusive proposition built on solus or tantum 'only, alone', and the key question is whether the conjunctive analysis of the medievals will suffice. But whence this analysis?

While I have credited Peter of Spain (1972, 1992; Mullally 1945), Beaver \& Clark (2008: 15) follow Atlas (1991) in crowning William of Sherwood (Kretzmann 1968) as "primary progenitor" of what we shall call Theory C (for Conjunction) on the grounds of chronological primacy. But in fact our Petrus Hispanus (whoever he was - probably not the man later elected Pope John XXI after all, according to current thinking, but one of several other Iberian candidates; cf. Spruyt 2008) wrote his Tractatus and Syncategoremata sometime around 1230-45, while William's Syncategoremata date to around 1240-45. So they were pretty much contemporaries. Further, Peter cast a longer shadow; his Tractatus was the standard introductory logic text well into the $14^{\text {th }}$ century. More to the point, William may have been a closet asymmetricalist on the treatment of only rather than a true believer in Theory C. Note in particular this passage from the Treatise on Syncategorematic Words XI.6 (Kretzmann 1968: 71-2):

At my first professional talk, in April 1969, I proposed a new theory of only. In April 1992 at SALT II at OSU I proposed another new theory of only, and (as some have observed) I haven't stopped doing so since. I am honored to have been invited back to the second meeting of SALT at OSU, to unveil ONLY XL- "XL" for 40, and for this extra-large (if not one-size-fits-all) version. Overlapping subsets of this material were presented in Tel Aviv (July 1999), Chicago (Jan. 2000), Berlin (March 2001), Tokyo (May 2001), Reading (Sept. 2001), New Haven (April 2002), Pomona (April 2005), Potsdam (Dec. 2005), Swarthmore (April 2006), Anaheim (Jan. 2007), Leysin (March 2007), Chicago (May 2008), Seoul (July 2008), and San Francisco (Jan. 2009), and elsewhere before the 10-year statute of limitations. I am indebted to commentators at those sites and to Barbara Abbott, Patricia Amaral, Jay Atlas, Kent Bach, David Beaver, Susanne Bobzien, Brady Clark, Ariel Cohen, Ashwini Deo, Bart Geurts, Anastasia Giannakidou, Janet Hitzeman, Michael Israel, Jason Merchant, Jerry Sadock, Victor Sánchez Valencia, Scott Schwenter, and Debra Ziegeler for their thoughts and comments. In the spirit of my 1969 analysis, I can safely guarantee that only the author is responsible for any errors. 
It is asked why 'alone' [solus] is called an exclusive rather than an inclusive; for when someone says 'Socrates alone is running', Socrates is included under running but the others are excluded. It must be said that it is because the inclusion occurs not as a result of the force of the word but as a result of the statement as it is before the 'alone' is inserted into it. The exclusion, on the other hand,...does occur as a result of the force of the word.

In the Tractatus Exponibilium 21ff. attributed to Peter of Spain by Mullally (1945: 106-7), the exclusive particle solus or tantum is an exponible that unpacks into "an affirmative copulative proposition whose first part is the same proposition without only" - this is the "PRAEIACENS" Or PREJACENT - "and whose second part is a negative proposition denying the predicate of all others apart from the subject." It now appears irrefutable that - contra Mullally, Horn 1972, and Ducrot 1972: 64-Peter of Spain was not responsible for this Tractatus; cf. Peter of Spain 1972: LIV-LV, Ashworth 1972: 138). ${ }^{1}$ But the true Peter did sponsor the prejacent entailment (Syncat. Tract 3, cap. 9-10): Tantum homo currit; ergo homo currit ('only a man is running, therefore a man is running'), where running (currit) is asserted (ponitur) in homo. The general rule is "Omnia exclusiva vera reliquit suam preiacentem veram" ("Every true exclusive proposition preserves the truth of the prejacent'; Peter of Spain 1992: 110).

\section{Only NP and the Asymmetry Wars}

Forty years ago (Horn 1969: 98), I revisited the question of the proper analysis of the exclusive sentence in (1a) and its relation to the two meaning components (or, following exponibilia theory, exponents) in (1b) and (1c).
(1) a. Only Muriel voted for Hubert.
b. Muriel voted for Hubert.
c. Nobody other than Muriel voted for Hubert.
d. Muriel and only Muriel voted for Hubert.

On the traditional Theory C, (1a) simply entails (and asserts) both (1b) and (1c) and hence the conjunction of the two; on this approach, (1a) is indistinguishable from (1d). As we have seen, both Peter of Spain and his impostor endorse such an analysis; so too does Ockham (Summa Logicae II.17: 1980: 132-42): "Every exclusive proposition has two exponents: one affirmative and the other negative. For example, 'Only a man is an animal' has these exponents: 'A man is an animal' and 'Nothing other than man is an animal'."

Similar symmetricalist analyses of the exponents of only have been cosponsored, endorsed, or independently developed by a myriad of medievals and

\footnotetext{
${ }^{1}$ This same treatise on exponibles, whoever authored it in the $13^{\text {th }}$ or $14^{\text {th }}$ century, is also notable for providing perhaps the earliest direct reference to presupposition in the literature; the exponible inquantum 'insofar as' prcesupponit that a given predicate inheres in the subject and denotat that the term to which it attaches is the cause of that inherence (Mullally 1945: 112).
} 
moderns, ${ }^{2}$ including Walter Burley (Pinborg 1981), William of Sherwood (O’Donnell 1941, Kretzmann 1968), Taglicht (1984), Keenan \& Stavi (1986), von Fintel (1993), Giannakidou (2006), and especially Atlas (1991, 1993, 1996, 2005, 2007). But no matter how many signatures appear on the symmetricalist petition, the signatories must cope with the evidence for asymmetry that has been accrued over the last several decades (cf. Horn 1969, 1970, 1992, 1996). This evidence begins with the apparent cancellability, or more accurately suspendibility, of the prejacent, as reflected in the contrast between the hopeless (2a) and the marginal (2b), acceptable to most speakers when the epistemic modal is present.

a. \#Only Ann will pay her taxes on time, but maybe someone else will.

b. Only Ann will pay her taxes on time, and \#(maybe) even she won't.

Fronted only XP phrases license inversion as in (3) and negative polarity items are licensed outside the focus of only XP and only $C N$ phrases; $(4 \mathrm{a}, \mathrm{b})$ are cited by Klima (1964: 311) as evidence for the "affective" status of only, supporting the essentially negative character of only contexts, despite the positive prejacent.

a. Only vegetables and fruit does she eat.

b. $\{$ Only on Thanksgiving/*Even during Lent $\}$ does he eat meat.

a. Only young writers ever accept suggestions with any sincerity.

b. Only his sister will expect him to write any more novels.

Such data suggest that the negative commitment of an only sentence, e.g. (1c), counts for more than does its positive commitment, e.g. (1b). Similarly, as noted in Horn 1969, a negative answer to an only-question seems to commit the speaker to the falsity of the exclusive rather than prejacent. When asked "Did only Muriel vote for Hubert?", my "No" response seems to commit me to the proposition that someone other than Muriel did, while retaining the assumption that she did.

Once we start down the asymmetricalist road, we may reach the conclusion that the prejacent of an only sentence is not entailed after all but rather semantically presupposed (Horn 1969), or perhaps conventionally implicated or pragmatically presupposed (Horn 1979), or maybe just conversationally implicated (McCawley 1981: 227, Horn 1992, Ippolito 2006, van Rooij \& Schulz 2007) — or perhaps it could simply be ignored altogether (Geach 1962: 187). (See Horn 1996 for a more detailed chronology of these approaches.)

While I'm sympathetic to the spirit of the asymmetricalist proposals noted above - and not just because I've endorsed most of them at one time or anotherI now side with Atlas in finding them flawed in the letter. In particular, semantic asymmetricalists cannot easily explain away Atlas's observation that simple cancellations of the prejacent in contexts like $(5 \mathrm{a}, \mathrm{b})$ are unsalvageably bad.

${ }^{2}$ I am indebted to Victor Sánchez Valencia for joining me in the quest for early medieval sources. The oldest we managed to locate in this connection is Abelard (1079-1142), whose analysis of (i) into the conjunction in (ii) appears in Tractatus III (Topica) of his Dialectica (Abelard 1970: 332-33). See Horn (1996: 1) for a more complete list of Abelard's descendants.

(i) Socrates tantum est Socrates.

'Only S. is S.'

(ii) Socrates est Socrates et nulla alia res est Socrates. 'S. is S. and nothing else is S.' 
a. \#Only Hillary trusts Bill, and (even) she doesn't.

b. \#I love only you, but I don't love you either.

Further, as Atlas has stressed, only $N P$ cannot be a standard downward monotone (downward-entailing [DE]) operator, given that (6a) fails to entail (6b).

(6) a. Only Socrates entered the race.

b. Only Socrates entered the race early.

Indeed, eight centuries earlier Peter of Spain (1992) had observed a similar lack of entailment either way between (7a) and (7b), a fact that follows from Theory C.
a. Only Aristotle moves.
b. Only Aristotle runs.

Nor do asymmetricalists always have intuition on their side. In Horn 1992, 1996, I defended McCawley's strong asymmetricalist approach on which (1a), while entailing (and asserting) (1c), merely presupposes (1b). In this way, (1a) is semantically distinct from (1d), which entails/asserts both positive (1b) and negative (1c) components, whence the conclusion (Horn 1992: 182) that "II love you] does not follow from [I love only you] by virtue of semantics." Predictably, Atlas (1993: 314ff.) was not convinced:

[This] consequence strikes me as so outrageously counter-intuitive as to be a reductio of the theory. The idea that simultaneously $I$ love only you could be true while I love you is false just seems crazy to me...I just have a very hard time with Horn's theory about the truth-conditions of I love only you.

So, in truth, do I.

This brings us back to Theory $\mathrm{C}$, with its own problems, especially those posed by the polarity licensing properties of only. But Atlas's arguments here are roughly as persuasive as my own doctrine on love. Atlas (1993: 313) begins by distinguishing examples like (4) above and his (8a) from $(8 \mathrm{~b}, \mathrm{c})$ to support his position that "only is not, in general, a trigger for Negative [Polarity] Items".

a. Only John ever suspected David Alexander.

b. *Only Bill wants Sam to finish the report until Friday. ${ }^{3}$

c. *Only Phil will give Lucy a red cent.

Since then, the battle has raged on between those who see that English only as a garden-variety NPI licenser (Horn 1996, 2002) and those who find such NPI

\footnotetext{
${ }^{3}$ In Horn 1970, the unacceptability of (8b) is attributed to restrictions on the distribution of strong NPIs like non-durative until, typically treated in the recent literature by distinguishing simple DE environments like only that license any, ever, and the minimizers and more restrictive-e.g. anti-additive and antimorphic - environments that are required by strong NPIs. (See e.g. van der Wouden 1997.) While (8c) may well be awkward, other minimizers (lift a finger, say a word, touch a drop, sleep a wink) are impeccable in the scope of an only NP subject.
} 
licensing effects to be chimerical (Atlas 1996, 2002, 2005; cf. Giannakidou 2006 on the status of only as a "renegade" licenser). Atlas (1996: 285-86) is in fact willing to grant that only $C N$ is DE (and NPI-licensing), while continuing to maintain that only with NP focus (more precisely only $a$, where $a$ is an individual constant) is non-monotonic and hence not a polarity licenser (nor a "negative item"): it only seems to license NPI minimizers because it's (i) a focus operator and (ii) a pseudo-anti-additive quantifier.

For (i), he cites the (putative) parallel between only and its fellow focusparticle even and bare focus in licensing (some?) minimizers (Atlas 1996: (22k)).

\{Only Phil/Even Phil/PHIL\} would lift a finger to help Lucy.

Unlike only NP, which licenses a wide range of NPIs (although not those of the strictest variety, e.g. in weeks, until midnight), even NP and bare-focused subjects come up spectacularly short, even with the most trigger-happy polarity items:

a. $\{$ Only Phil/*Even Phil/PHIL $\}$ ate any of the squid.

b. $\{$ Only Phil/*Even Phil/PHIL $\}$ could sleep a wink with that racket.

In general, a constituent of the form only $+\mathrm{NP} / \mathrm{PP} / \mathrm{CN}$, or of the form the only $C N$, will license weak and (some) medium-strength NPIs outside its focus. ${ }^{4}$ In these examples from Horn (1996: 17-18), replacing only with even rules out the NPIs (in wavy underline; focus of only indicated with small caps).

a. I've only ever gone there ONCE.

b. I only go there $\{$ SOMETIMES/*EVER $\}$.

a. I only eat any meat WHEN I'M UPSET.

b. I eat meat only WHEN I'M UPSET ABOUT \{SOMETHING/?*ANYTHING\}.

a. Only ONCE have I ever been there.

b. *Only EVER \{do I go there/have I been there .

a. Only WHEN I'M UPSET do I ever eat any meat.

b. ?*Only WHEN I'M EVER UPSET ABOUT ANYTHING do I eat meat.

a. The only one who said a word was CHRIS.

b. \#Chris only SAID A WORD. (literal only; no "NPI idiom" reading)

To the extent that NPIs are licensed in (9) with even or bare focus, this is a fact about the liberation of lift a finger from its minimizer status. Thus we could imagine a command "Lift a finger, for God's sake" parallel to the old billboard (recently revived by environmental groups in Australia) beseeching readers to "Give a damn!"5 When we disambiguate in favor of the true minimizer reading, the acceptability of the even and bare focus versions is seriously degraded:

$\{$ Only Phil/*Even Phil/*PHIL $\}$ so much as lifted a finger to help Lucy.

\footnotetext{
${ }^{4}$ While NPIs do occur within the focus of only, their appearance is in fact non-problematic; cf. Horn (1996: Appendix), Beaver \& Clark (2008: 189-90), and references therein.

5 Consider also the title of Davina Kotulski's book Why You Should Give a Damn About Gay Marriage or the Jo Dee Messina country song (and T-shirt spinoff) "My Give A Damn's Busted".
} 
As to why (some) minimizers should occur in environments like that of (9) or the Give a damn billboard, I would suggest that it's easier to liberate an NPI from licensing requirements if it's an unpaired item (like the minimizers or budge) than if it's a member of an NPI/PPI polarity couple (any/some, ever/sometimes, yet/already, \%anymore/still). Note along the same lines that liberated minimizers can often appear naturally in direct denials, while coupled NPIs cannot:

a. I did so \{lift a finger to help you/eat a bite of my octopus soufflé\}.

b. I have so $\{(*$ ever $)$ taken a course on polarity/eaten (*any) raw squid $\}$.

Like any and ever, NPI minimizers are licensed by only but not by focus per se.

As for (ii), while I cannot review Atlas's case for pseudo-additivity here (but see von Fintel 1999), this property does not seem to be criterial for NPI licensing by only. While only $a$ is PAA on the Atlas definition, only $\mu N$ (where $\mu$ is a cardinal) is non-negative for Atlas - not even pseudo-anti-additive, much less DE_-yet it is as adept at licensing as only $N P$ or only $C N$ :
a. Only Republicans ever believed that story.
[DE for Atlas]
b. Only Rush ever believed that story.
[not DE but PAA]
c. Only three senators ever believed that story.
[not DE or PAA]

Indeed, an empirical study of NPI licensing across a variety of triggers and a variety of polarity items (De Dekker et al. 2005) finds that only 5 babies matches the competition - no one, few babies, not every baby, at most 2 babies - at licensing such NPIs as ever, slept a wink, much, in ages, at all, and yet. In addressing this result, Atlas (p.c.) has suggested that only $\mu C N$ (pseudo-)licenses weak NPIs for the same reason that exactly $\mu C N$ does (cf. Linebarger 1987: 373). But is this tenable? Compare, for example:

(19) a. \#Exactly $48 \%$ of the voters ever believed any of that bull.

b. Only $48 \%$ of the voters ever believed any of that bull.

a. \#Exactly $68 \%$ of eligible U.S. voters ever bother to register to vote.

b. Only $68 \%$ of eligible U.S. voters ever bother to register to vote.

The licensing of polarity items by exactly $n$ is highly constrained-requiring, inter alia, relatively small values for $n$ - and arguably involves an allusion to a relevant implicature, as Linebarger plausibly proposes. But, contra Atlas (and Giannakidou 2006), there is no evidence that licensing by only $n$ is equally constrained; see again De Dekker et al. (2005), where substitution of exactly 5 babies for only 5 babies in the tested frames would radically alter the results.

\section{The Existentialists' Dilemma}

In Horn 1996, I attempt to ground the NPI licensing behavior of only XP phrases in the converse relation holding between exclusive and universal propositions, as recognized since the medievals: 
Thus, for example, a popular TV show and dating service in Germany, "Nur die Liebe zählt", literally 'Only love counts', arose as a translation of the Beatles' song "All you need is love". Given this interdefinabilility, enunciated by Ockham (1980: 141) among many others-

There is a valid consequence from an exclusive proposition to a universal proposition with the terms transposed, and conversely ...Therefore this consequence is valid: "Only what is necessary is true; therefore everything true is necessary".

-it seems reasonable to suggest that the nuclear scope of an exclusive licenses NPIs in the same way, and for the same reason, as the restrictor of $\forall$, both essentially reduced to a matter of existential import, as reflected in (22). ${ }^{6}$

(22) a. Only symmetricalists have ever had any problems with this.

b. Everyone who has ever had any problems with this is a symmetricalist.

While this seemed like a good idea at the time (cf. Horn 1996, drawing on Walter Burley's "De exclusivis", in Pinborg 1981 and de Rijk 1985) and does in fact make some successful predictions, matters are not so simple.

One context designed to distinguish among candidate theories on the status of the prejacent involves variants on a bet I proposed $(1996 ; 16)$ whose results seemed (to me) to favor the existential (or "weak presupposition") theory; more recently, Roberts (2006) and Beaver \& Clark (2008: 218ff.) have challenged both the central intuitions I reported and the interpretations, and I will not pursue the point here. In any case, as shown by both Ippolito (2006: 12) and van Rooij \& Schulz (2007: 212), it must be the prejacent and not the existential proposition that is implied or presupposed by an only statement with conjoined NP focus. Thus, (23) commits the speaker to the proposition that Muriel and Lyndon voted for Hubert, not just to the claim that the set of Hubert-voters was non-null.

Only [Muriel and Lyndon] $]_{F}$ voted for Hubert

Beaver \& Clark (2008: 224) extend the observation to not only contexts, where for example in $(24 a, b)$ the "presupposition" is that the referent of the focused NP-Mary and [Mary and Jeff] respectively—smoke, not just that someone does.

(24) a. Not only [Mary $]_{F}$ smokes.

b. Not only [Mary and Jeff $]_{F}$ smoke.

(Beaver \& Clark 2008: (9.15))

(Beaver \& Clark 2008: (9.17))

We will thus assume that whatever the status of the positive inference from an only sentence may be, it is the prejacent that constitutes the content of that

\footnotetext{
${ }^{6}$ Indeed, Clark (2006; cf. Beaver \& Clark 2008: 201) argues that the NPIs licensed by only are exactly the same as those licensed by the restrictors of universals, precisely as predicted by conversion principle in (22), viz. any, ever, and the minimizers. We return to this point below.
} 
inference (see Beaver \& Clark 2008 for related discussion). But what is the nature of that inference?

\section{Capturing the Via Media}

Given the problems with the Theory $\mathrm{C}$, it would be nice if we could salvage a DE account for all instances of only licensing, but that door is closed behind us with a familiar figure standing guard, as von Fintel (1999: 103ff.) has aptly observed:

To establish the DE-ness of only, we need to be convinced that in a situation where it is true that only John ate vegetables for breakfast it is also strictly speaking true that only he ate kale for breakfast. It may be misleading and odd to actually assert the conclusion but that does not mean that it isn't true. The problem with this account is that it is highly controversial that only-sentences can in fact be true in situations where their positive component is not satisfied. If one believed that the positive component is a presupposition in any semantically relevant sense, one would not assent to such an assessment. And if one thought that the positive component is in fact an entailment (albeit perhaps 'backgrounded' in some way), one would also decline to accept Ladusaw's pleading [for the DEness of only]. And there are plenty of people these camps (to appreciate the heat of debate one just has to look at Atlas 1993, $1996 . .$. It is hard to imagine I could emulate the incredulity of the reaction by Atlas to the asymmetric analysis of only, cf. Atlas (1996: 280), so let me quote a representative passage:

[Assume Socrates saw a mangy dog in the agora, which escaped his companions' notice.] Then Socrates saw an animal is true. On the downward monotonic view, it is entailed-entailed!! - that Only Socrates saw a snow leopard. That is, in every possible model (world) in which Only Socrates saw an animal is true, Only Socrates saw a snow leopard is true in that model... So much the worse for downward monotonicity in only a sentences.

While there are, of course, valiant attempts to justify a semantics for only where the inference that so offends Atlas' sensibility is ...truth-preserving, one cannot deny the force of the objection.

What we seek is an approach that concedes the non-DE status of only environments while coming to terms with polarity licensing and the other markers suggesting asymmetry. Given our stock example in (1),

(1) a. Only Muriel voted for Hubert.

b. Muriel voted for Hubert.

c. Nobody other than Muriel voted for Hubert.

we have the menu of options in Table 1 for coping with the Janus-faced character of the prejacent: when is an entailment not (quite) an entailment? 
Source

\begin{tabular}{|c|c|}
\hline $\begin{array}{l}\text { Medievals (Abelard, Peter } \\
\text { of Spain, William of } \\
\text { Sherwood, Ockham); Atlas } \\
\text { (1991 et seq.) et plur. al. }\end{array}$ & $\begin{array}{l}\text { "Theory C": Prejacent is entailed/ } \\
\text { asserted (pure symmetricalist } \\
\text { analysis); (1a) is a simple conjunction } \\
\text { of (1b) and (1c) }\end{array}$ \\
\hline Geach 1962: 187 & $\begin{array}{l}\text { entirely disregarded; }(1 \mathrm{a})=(1 \mathrm{c}) \text {, } \\
\text { so ' } \mathrm{F}(\text { only } a) \text { is true if } \mathrm{F} \text { is true } \\
\text { of nothing at all' }\end{array}$ \\
\hline $\begin{array}{l}\text { Horn 1969, 1972; } \\
\text { von Fintel 1999 (sort of) }\end{array}$ & $\begin{array}{l}\text { (Semantic) presupposition; ( } 1 \mathrm{a}) \text { is } \\
\text { neither true nor false if }(1 \mathrm{c}) \text { is false }\end{array}$ \\
\hline Horn 1979 & $\begin{array}{l}\text { Pragmatic presupposition or } \\
\text { conventional implicature; (1a) is } \\
\text { inappropriate but true if }(1 \mathrm{c}) \text { is false }\end{array}$ \\
\hline $\begin{array}{l}\text { McCawley 1981; Horn 1992; } \\
\text { Ippolito 2006; van Rooij \& } \\
\text { Schulz } 2007\end{array}$ & $\begin{array}{l}\text { Conversational (scalar) implicature; } \\
\text { (1b) (normally) follows from assertion } \\
\text { of (1a) by Grice's maxim of Quantity }\end{array}$ \\
\hline $\begin{array}{l}\text { Horn 1996; } \\
\text { von Fintel 1999 (sort of); } \\
\text { Beaver \& Clark } 2003\end{array}$ & $\begin{array}{l}\text { Prejacent is not directly presupposed; } \\
\text { (1b) follows indirectly from (1a) via } \\
\text { presupposition of existential prop.; } \\
\text { F (only a) presupposes } \exists x F x\end{array}$ \\
\hline $\begin{array}{l}\text { Horn 2002; } \\
\text { Schwenter } 2002\end{array}$ & $\begin{array}{l}\text { Prejacent of only (like polar component } \\
\text { of almost, barely) is an assertorically } \\
\text { inert entailment, transparent to NPI } \\
\text { licensing and other diagnostics }\end{array}$ \\
\hline Roberts 2006 & $\begin{array}{l}\text { Conventionally presupposed; } \\
\text { akin to Horn } 2002 \text { analysis }\end{array}$ \\
\hline Beaver \& Clark 2008 & $\begin{array}{l}\text { speaker of (1a) presupposes (within } \\
\text { discourse-based theory) that (1b) is } \\
\text { strongest true answer to current question }\end{array}$ \\
\hline
\end{tabular}

Table 1

The recipe for seizing the middle ground that von Fintel (1999) offers is STRAWSON ENTAILMENT. Essentially, one proposition Strawson-entails another if the entailment goes through modulo the satisfaction of its presuppositions (cf. Hoeksema 1986 for a precursor of this idea). Strawson-downward entailment can be defined derivatively: A function $f$ of type $\langle\sigma, \tau>$ is Strawson-DE iff for all $\mathrm{x}, \mathrm{y}$ of type $\sigma$ such that $\mathrm{x}=>\mathrm{y}$ and $f(\mathrm{x})$ is defined, it holds that $f(\mathrm{y})=>f(\mathrm{x})$. (The underlined part is what turns this into an instance of Strawson-DEness.) Only NP is not DE, since Only Chris ordered Thai curry does not entail Only Chris ordered Thai red curry (perhaps nobody ordered red curry), but it does entail Only Chris ordered Thai red curry if anyone did. Thus, only NP is Strawson-DE in that if the presuppositions of only are satisfied (and hence the prejacent is true), the set-to-subset inference is valid.

But a question naturally arises: is only a $F s$ always undefined when $a$ does not $F$ ? (25a) seems false, rather than undefined, if only Atlas can lift the rock, and if the Red Sox win 103 games and no other team is in triple figures, my wager in (25b) is lost, and not just trapped in Strawsonian limbo. 
a. Only Hercules can lift that rock.

b. I bet you that only the Yankees will win over 100 games.

On the other hand, if nobody can lift the rock, or if no team wins more than 99 games, it's less clear how to assess the truth of these statements (see Beaver \& Clark 2008: 218ff. on "Horn's Bet" and related contexts for some significant complications). This may suggest that the Strawson-DE approach can be made to work if we take the presupposition to be not the prejacent itself (Hercules can lift that rock for (25a)) but rather the existential premise (Someone can...)? While von Fintel himself informally accepts this approach (1999: 104), we have already seen that such existentialist analyses ultimately prove untenable. ${ }^{7}$

A more general question is just what sort of theory of semantic presupposition and presupposition failure we are prepared to accept. While I agree with von Fintel (1999: 107) on the desirability of navigating a via media between the Scylla of the symmetricalists and the Charybdis of the asymmetricalists, I do not view the Strawson-DE approach as the only contender for a happy medium.

Theory $\mathrm{C}$ proponents typically depict (1a) as entailing and asserting (1b) and (1c), using the two verbs interchangeably. But is this identification either necessary or desirable? When Peter of Spain (1992: 110), formulating the archsymmetricalist analysis of the prejacent, maintains "Propositio exclusiva ponit suam preiacentem", de Rijk glosses this as the claim that any exclusive proposition asserts its prejacent, but the verb in question-pōno, pōnere, posui, positus - can be variously rendered (as in Lewis 1889) as 'to lay down as true, state, posit, fix, assume, assert, maintain, allege'. A lineal descendant of this verb figures in Ducrot's distinction (1972: 63-65) between the posé and the présupposé; he notes that the negation of the exclusive in (26a) is usually taken to bear on the posé (26c), not the présupposé (26b); thus, the prejacent is not posé.
a. Seul Dieu est aimable.
'Only God is lovable'
b. Dieu est aimable.
'God is lovable'
c. Aucun être différent de Dieu n'est aimable.
'No being distinct from
God is lovable'

\footnotetext{
7The quiz on the "WayWeird" e-mail list's Valentine's Day Special, Feb. 14, 2006, sheds curious light on this dispute. The quiz is given here, with the site's answer and commentary:

Weird Facts! Which one of these three facts are false!

1) Swans are the only birds with penises!

2) Mountain sheep are the only animals born with horns. Both males and females are born with bony knobs on the forehead.

3) Honey is the only food that does not spoil. Honey found in the tombs of Egyptian pharaohs has been tasted by archaeologists and found edible!

Which one of the facts was false? If you guessed number 1 then you are wrong! The false fact is actually number 2 ! Actually, Giraffes are the only animals born with horns! Both males and females are born with bony knobs on the forehead.

According to other internet sources, however, no birds have penises. Yet 1) evidently does not thereby become a false fact like 2), but is presumably just undefined. Thus the commentary by www.WayWeird.com is consistent with von Fintel (1999) only on the existentialist analysis, a point on which the web site is inexplicably silent.
} 
More generally, it is what is posé that falls within scope of negation, assertion, interrogation, etc. Ducrot's sense of the posé prefigures current notions like those of "proffered" or "at-issue" meaning (as in Roberts 2006 and Potts 2005 respectively). But just where does this leave the status of the prejacent?

I have been arguing for some time (Horn 1996, 2002) that even if we grant entailment status to both (1b) and (1c), not all entailments are created equal. Semantically entailed material that falls outside the scope of the asserted, and hence potentially controversial, aspect of utterance meaning (Stalnaker 1978) counts as ASSERTORICALLY INERT and is hence effectively transparent to NPIlicensing and related diagnostics of scalar orientation (Horn 2002: (28)). In particular, we can accept that the only NP statement does indeed entail both the prejacent and the exclusive propositions, while maintaining that only the latter component is asserted, the prejacent being assertorically inert. ${ }^{8}$

Given the contrast between assertion and entailment, we can redefine the scopal diagnostics Karttunen \& Peters (1979) posited for conventional implicature as diagnostics for non-assertion. As seen in (27), material that is presupposed or conventionally implicated-or, on our account, non-asserted-scopes out of factives. The prejacent of the only clause, i.e. the proposition that the wealthy will benefit from the tax cuts, is outside the assertive scope of the higher factives.

a. I just discovered that only the wealthy profited from the tax cuts.

b. It's too bad that only the wealthy profited from the tax cuts.

If the model contains the prejacent, an only statement can still be asserted or questioned, but if contains the exclusion, this is ruled out (pace Atlas 2007: 13):

(28) a. I know the wealthy will profit, but will ONLY the wealthy profit?

b. \#I know nobody besides the wealthy will profit, but will ONLY the wealthy profit?

c. We all know nobody besides the wealthy will profit, but guess what: (\#only) the wealthy will profit.

On this account, it is downward assertion, not downward entailment as such, that licenses NPIs - or at least any, ever, any, and the minimizers. For Giannakidou (2006), on the other hand, only and emotive factives are "renegade" NPI licensers in languages like English, a conclusion based in part on the fact that in languages such as Greek, NPIs are not licensed in these contexts (Giannakidou 1998, 2006):

\footnotetext{
${ }^{8}$ This approach was partially foreshadowed in a remark of the arch-conjunctionalist Jay Atlas himself (1991: 139): "[I]n asserting Only a is $F$, we do not thereby assert $a$ is $F$... What we do assert entails a is F, but it does not 'say' it" (emphasis in original). Perhaps because his account, unlike the current one, stipulates that Only a is $F$ does "say" that exactly one thing is F, Atlas does not draw the same conclusions from his assertoric asymmetry. As we have noted, Atlas has maintained a consistent, if unpersuasive, skepticism on the status of only $a$ as a licenser of NPIs, so he does not in fact put the asymmetry to work. An additional problem I have had with Atlas's conjunctive unpacking of (i) as (ii) is my discomfort with the unnaturalness of the latter.

(i) Only Muriel voted for Hubert.

(ii) Exactly one individual, and at most Muriel, voted for Hubert.
} 
Giannakidou stresses the fact that only clauses are veridical and the fact that they don't license all NPIs. But first, veridicality is not a deal-breaker as long as the relevant entailment is assertorically inert and second, licensing isn't a binary thing, as we have noted. Indeed, even those restrictive polarity items that Giannakidou sees as requiring overt negative licensers (the examples in (30) are reproduced from her (43)) do not always require them, as seen in (31):
a. *Only Bill came either.
b. *Only Bill is all that intelligent.
c. *Only Bill arrived until Friday.

a. Few of MY friends could make it here either.

b. If he's all that smart, why isn't he rich?

c. I'll be damned if I'll quit until I absolutely have to.

Clark (2006)'s response to Atlas implicitly carries against Giannakidou as well: the class of NPIs licensed by only in English includes (at least) those also licensed by the restrictors of universals - any, ever, and the minimizers - and Giannakidou herself endorses the legitimacy of universals as licensers. ${ }^{9}$

Do languages like Greek require downward entailment as opposed to downward assertion to rule out (29) and similar sentences? No-for two reasons. First, DEness isn't necessary for licensing in Greek. Disjunctive and wantcontexts permit unstressed kanenas, as Giannakidou (1998) has documented; cf. e.g. (32), courtesy of Jason Merchant (p.c.)

\section{(32) I bike kanenas mesa i afisame ta fota anamena.}

lit. 'Either n-one came in or we left the lights on'

(Note the impossibility of the corresponding sentence in English: *Either anyone came in or...). Second, DEness isn't always sufficient. At most $n$, unlike only $n$, seems to establish a true downward entailing environment: if at most 5 students passed, then at most 5 students got A's. (Notice that this is a question of actual DEness, not the Strawson DEness proposed for only in von Fintel 1999.) Yet the equivalent expression to at most fails to license even weak NPIs in Greek (Anastasia Giannakidou, p.c.):

${ }^{9}$ Clark (2006) maintains that the two sets of NPIs are actually identical, but there is reason to believe exclusives are actually stronger licensers than universals. Consider (i), from the New York Times coverage of the Ryder Cup $(9 / 25 / 05$, D5) and (ii) from a reader's review of Mary Karr's The Liar's Club on amazon.com:

(i) Of the four American rookies, only Zach Johnson (1-2-1) did much.

(ii) Only James Ellroy's 'My Dark Places' and Mikal Gilmore's 'Shot Through The Heart' hold a candle to this in my experience, and I've read a few.

The corresponding universals are palpably less adept as triggers:

(iii) \#Every American rookie who did much had practiced assiduously on the course.

(iv) \#All the books that hold a candle to The Liar's Club were on display on the table. 
Thus, we see that in Greek, at most $n$ and only $n$ are equivalently non-licensers, while in English they're equivalently (medium-strength) licensers (cf. again De Decker et al. 2005), so it can't be DEness as such that's relevant in either case.

The pure DEness of at most statements is in fact more complicated than it appears. On their conjunctive epistemic analysis of at most n, Geurts \& Nouwen (2007) would unpack (34a) into a conjunction of (34b) and (34c).

a. At most 3 people have proved this theorem.

b. It is (epistemically) possible that 3 people have proved this theorem

c. for $n>3, \neg$ It is possible that $n$ people have proved this theorem]

The obvious question arises under this analysis: Why is at most $n$ an NPI licenser, given the conjunctive and hence apparently non-monotonic expansion in Geurts \& Nouwen 2007? Notice that as seen in (34), the quasi-negative behavior of at most $n$ nominals is shared by that of the upper-bounding proposition in (35c) but not by that of the positive epistemic proposition in (35b).

a. At most 3 people have ever proved this theorem.

b. *It is possible that 3 people have ever proved this theorem.

c. It isn't possible that more than 3 people have ever proved this theorem.

The key is to recognize that once again the symmetry in the semantics may conceal a crucial asymmetry at the level of what is asserted. Because the entailment in (34b) is assertorically inert, at most $n$ asserts only the negative proposition in (34c) and thus counts as effectively downward monotonic.

One last point on the relation of only to at most: while the former normally entails (without asserting) its prejacent, there are contexts in which this seems not to hold and the two upper-bounding particles converge. (36), a statement that applicants for Yale University parking permits were recently required to affirm,

I also agree that only one of my vehicles will be parked in any Yale University lot at any one time.

was not likely interpreted as committing the recipient of the sticker to stationing a car in a Yale lot at all times.

It should be acknowledged that not everyone has been won over by the compelling arguments for assertoric inertia. Besides the predictable skepticism of Atlas $(2002,2007)$, we might touch on another recent critical review:

Horn (2002), having previously argued for a strong presupposition and then for a weaker one, gave up on the presupposition altogether. The position he ended up supporting is that both the positive and negative components form part of the entailed meaning of only. However, the positive component suffers from a peculiar impediment Horn calls inertia, an impediment which apparently prevents the positive component from getting caught up in the hustle and bustle that normal entailments face in their 
everyday life. For example, inert entailments do not like to be the main target of an assertion, a negation, or an emotive attitude. In fact, they behave suspiciously like presuppositions.

(Beaver \& Clark 2008: 244-45)

To which a response might begin by muttering "... as if we knew what THOSE were." A semantic presupposition is a necessary condition for $\mathrm{S}$ to be true or false; $\mathrm{S}$ is undefined if one of more of its presuppositions fails. A pragmatic presupposition (or conventional implicature) is a condition on felicity whose truth is irrelevant to the truth conditions of S. An entailment (whether inert or hustlybustly) is a necessary condition for $\mathrm{S}$ to be true, its falsity a sufficient condition for $\mathrm{S}$ to be false. Even when its projection properties are similar to those of (some varieties of) presupposition, its contribution to sentence meaning is distinct.

\section{The Proximative Exponibles}

The position defended here and in Horn 2002 accounts for the behavioral asymmetry between the prejacent and the exclusive components of only constructions without predicting that the former can in fact be directly cancelled. Nor (unlike the neo-Strawsonian account of von Fintel 1999) does it assume the viability of semantic presupposition. The distribution of two other exponibles, the proximative adverbs barely and almost, provides additional support for the assertoric inertia approach over those of its rivals (see the discussion in Horn 2002, Schwenter 2002, and Amaral 2007).

As seen in (37),

(37) a. Gore almost won the election. $>$ a'. Gore didn't win the election.

b. Bush barely won the election. $>\quad b$ '. Bush won the election.

almost is in part semantically negative - from (37a) it follows that (37a') - while barely (= almost not) is correspondingly in part positive-from (37b) we can conclude that (37b') is true. As with only, the most straightforward account of the meaning contributed by almost and barely is an analysis involving conjunction, in this case involving what Sevi (1998) dubs the proximal and polar components (cf. Hitzeman 1992, Rapp \& von Stechow 1999):

a. Gore almost won.

a'. CLOSE-TO [Gore won] (PROXIMAL) ^ ᄀ[ Gore won] (POLAR)

b. Bush barely won. (= Bush almost didn't win)

b'. CLOSE-TO $\neg[$ Gore won] $($ PROXIMAL) $\wedge$ [ Gore won] (POLAR)

Yet it's not almost, the approximative with the negative polar component, but barely, despite its positive polar component, that licenses NPIs:

(39) a. \#She almost \{moved a muscle/touched a drop/spoke to anyone\}.

b. She barely \{moved a muscle/touched a drop/spoke to anyone\}. 
This result is problematic for Linebarger's (1987) theory of indirect polarity licensing, given the fact that (40a) entails, if it is not logically equivalent to, (40b); as seen in (41), however, the intimate semantic relation between almost doing something and not quite doing it fails to distinguish their behavior with respect to the distribution of NPIs.

(40) a. I almost complete my assignments.

b. I didn't quite complete my assignments.

(41) a. I almost completed \{some/*any\} of my assignments.

b. I didn't quite complete any of my assignments.

Atlas (1997) supports the non-monotonicity (non-DE-ness) of barely VP by observing that if John is barely six feet tall, it doesn't follow that he's barely [six feet tall and blond], to which we might add the observation that to be totally naked is not to be barely dressed.

But if barely is not as positive nor almost as negative as the implications in (37) suggest. Even Sevi, for whom Almost $P$ entails/asserts not $P$ and Barely $P$ entails/asserts $P$, acknowledges that these polar assertions are "somehow "backgrounded" or less "prominent" than the corresponding proximal assertions: 10 "almost is "positive" and barely is "negative" in some sense' (Sevi 1998: 32). But in WHAT sense? How can we elucidate Sevi's scare quotes?

Evidence for the positivity of almost and the negativity of barely (cf. Ducrot 1973; Sadock 1981; Sevi 1998; Horn 1996, 2002) comes from polarity licensing ((39) above), from inversion (\{Barely/*Almost $\}$ had we arrived when ...), and from the role of approximatives in argumentation. I'm delighted if my laptop is almost working and concerned if it's barely working, even though it's in the former case that it actually functions. If our tank is barely half full, we'd better stop to fill it, while if it's almost half full, we can blithely drive on, although it contains less gas in the latter case. And as Ziegeler (2000) points out, the polar component fails to support causal explanation: if I admit that I almost moved to Canada because of the war, the war could only have been an insufficient motive for emigrating, not a reason for my staying put.

We might try building in the asymmetry of the polar and proximative components semantically, as in Sadock 1981 where [almost $p$ ] is true iff $p$ is true in a world not very different from the real world; it conversationally implicates (rather than entailing) $\neg$ p. But as with our objections to the parallel McCawley/ Horn/Ippolito/van Rooij \& Schulz implicature treatments of only, the inferences in (37) act like true entailments, especially with respect to (non-)cancellability. Space prevents a full-dress rehearsal of the details here (see Horn 2002, to appear for summary and references and Atlas 2005: Appendix 2 for a recent addendum), beyond noting the anomaly of (42a,b) (the former from Sadock 1981).

(42) a. \#Bill almost swam the English Channel, and (in fact) he did swim it.

b. \#Gertrude barely swam the English Channel, and (in fact) she didn't.

\footnotetext{
${ }^{10}$ On Sevi's analysis, [Almost P] asserts that $\mathrm{P}$ is true at the closest index to the index of evaluation and [Barely $\mathrm{P}$ ] that $\mathrm{P}$ is false at the closest index to the index of evaluation, where 'closeness' may involve scalar strength, possible worlds, time intervals, or standards of precision.
} 
We are thus confronted with another instance of quasi-asymmetry, where a straightforward conjunctive analysis will not suffice, yet demoting the polar component to a conversational implicature empirically mispredicts. Indeed, the parallels between only and the proximatives are compelling. Here too the relevant (polar) components scope out of emotive factives; $(43 \mathrm{a}, \mathrm{b})$ express regret that the bailout came close to passing or to not passing, respectively (not regret that it failed or succeeded), just as (43c) complains that no non-wealthy were helped.

(43) a. It's too bad that the bailout almost passed.

b. It's too bad that the bailout barely passed.

c. It's too bad that the bailout helped only [Fthe wealthy].

In the spirit of von Fintel (1999), we might be tempted to seek the middle way of Strawson entailment. But can we really claim that Gore barely won presupposes that Gore won and is undefined if Gore lost? If (as I would submit) it's false under those conditions rather than undefined, barely $V P$ can't be Strawson-DE, and von Fintel's line on only fails to generalize to barely.

Rather, the polar component of the meaning of almost VP and barely VP, like the prejacent of only, is entailed but assertorically inert, predicting the quasimonotonic behavior of the relevant clauses. Other quasi-conjunctive exponibles allow a similar analysis; in particular, exceptives (Everybody but Cheney would call that torture; Nobody but Cheney would have done that) combine an asserted proposition (the excepted universal) with an non-asserted but (following von Fintel 1993) entailed proposition holding of the exception. Like Atlas (2002: 12), I "remain as unconvinced as ever that downward entailment can explain the distributional data of NPI licensing", but I place the blame on the "entailment" rather than on the "downward".11

\section{Entailment vs. implicature: a new Griceogloss}

We have reviewed the conflicting evidence for and against entailment- and implicature-based treatments of the polar component of proximatives and the prejacent component of exclusives, and proposed a resolution that involves adopting a pragmatically massaged form of the conjunction approach. A new diagnostic - or GRICEOGLOSS — is defined by mixed-outcome situations like those

\footnotetext{
assert exhaustivity fail to license NPIs in the absence of a dedicated exhaustivity marker:

(i) It's (only) [ $\left.{ }_{\mathrm{F}} \mathrm{Bush}\right]$ who has proposed tax cuts in wartime.

(ii) It's *(only) [ $\left.{ }_{\mathrm{F}} \mathrm{Bush}\right]$ who has ever proposed any tax cuts in wartime. license NPIs, as seen in (iii)-(v) from Beaver \& Clark (2003: 332):

(iii) People $\{$ only/*always $\}$ ever have [F cream of mushroom soup].

(iv) People \{only/?always $\}$ give a shit for [Fme].

(v) I \{only/?always $\}$ gave a damn because I thought [Fyou] did.
}

${ }^{11}$ We have seen that NPIs are not licensed by almost, which does not assert its relevant negative entailment. Note too that clefts and other focus expressions that implicate but do not

Similarly, always differs from only in not asserting exhaustivity, and correspondingly in failing to 
as illustrated in (44) and (45). When dealing with clear instances of conversational implicature, we get inclusive readings for the subset described.

a. 20 students tried to solve the problem. [includes any who solved it]

b. 20 students solved most of the problems. [includes any who solved all]

c. 20 students don't drink much. [includes any teetotalers]

Thus, if 5 of the students under consideration in (44a) did solve the problem, they constitute 5 of the 20 who tried to solve it. If 5 are teetotalers in (44c), again we have just 20 in all. But now compare the exclusives and proximatives:

a. 20 students almost solved the problem. [excludes any who solved it]

b. 20 students barely passed the test. [excludes those who failed]

c. 20 students solved only the last problem. [excludes those solving none]

If (45a) is true and 5 students solved the problem, we have a total of (at least) 25 students - the 5 who succeeded and the 20 who almost did. (45b) similarly takes the set of students who actually failed to be disjoint from the set of the 20 who barely passed (and thus did pass). And in (45c), we again require 25 students for the union of the 20 who solved just the last problem and the 5 who solved none of them. This last case contrasts minimally with the at most case in (46) and extends to the case of scalar only (asserting 'no more than') illustrated in (47).

(46) 20 students solved at most the last problem. [includes those solving none]

(47) a. 20 of the students are sophomores. [excludes freshmen + juniors]

b. 20 of the students are at least sophomores. [includes juniors]

c. 20 of the students are at most sophomores. [includes freshmen]

d. 20 of the students are only sophomores. [excludes freshmen + juniors]

Once again we see that conversational implicature does not suffice for the prejacent component of exclusives or the polar component of proximatives.

\section{The limbo of "epistemic cancellation"}

Georg Wilhelm Friedrich Hegel's reported last words, "Only one man ever understood me, and he didn't understand me", with their desperate attempt to cancel the prejacent, can be excused on the grounds that the man was, after all, on his deathbed at the time. For those who are not similarly in extremis, such cancellation is beyond the pale. But what of suspension, or epistemic cancellation? The putative possibility of sentences like $(48 \mathrm{a}, \mathrm{b})$ constitutes a central argument in the (independent) defenses by and Ippolito (2006) and van Rooij \& Schultz (2007) of a conversational implicature analysis of the prejacent of only.

(48) a. Only [Hillary $]_{F}$ trusts Bill, and perhaps even she does not. (vR \& S)

b. Only $[\text { Hillary }]_{F}$ trusts Bill, and maybe not even she does. (Ippolito) 
The claim that the prejacent is easier than the exclusive component to cancel (with an epistemic rider) has a paper trail. $(48 \mathrm{a}, \mathrm{b})$ are variants of similar ones in Horn (1996) such as (49a), or we could set our time machine dial a bit farther back - to Horn (1970: 322) — and arrive at (49b), fragrantly redolent of its era.

a. Only Kim can pass that test, and \#(it's possible) even she can't.

b. Only John smokes pot, and even he may have quit.

Even if exclusives with suspended prejacents are not impeccable, they contrast favorably with the impossible instances of suspension of the negative component:

a. \#Only Kim can pass that test, and/but (it's possible) someone else can.

b. \#Only John smokes pot, and/but Mary may too.

This contrast is especially vivid in cases in which the suspender is distinct from the original utterer; while the acceptability of $\mathrm{B}_{1}$ 's response below may vary (as indicated by the diacritic), $\mathrm{B}_{2}$ 's version is totally out.
A: - Only Hillary trusts Bill.
$\mathrm{B}_{1}$ : - You're right. ${ }^{\%}$ And what's more, maybe even she doesn't.
$\mathrm{B}_{2}$ : - You're right. \#But maybe Chelsea does too.

Atlas $(1996,2005)$ remains unconvinced of the significance of such distinctions: despite what Horn "incorrectly thinks" and "mistakenly believes", he avers, "there is no epistemic cancellation at all." But on the other side, we have not only the intuitions of semantic and pragmatic asymmetricalists (Ippolito, van Rooij \& Schulz, Horn, von Fintel) to rely on, but the testimony of the person on the street, or rather the blogger on the web. (52) provides googled instances in which the prejacents in a range of only phrases with different focus types is happily suspended or epistemically cancelled (cf. also Beaver \& Clark 2008: 99.6 for a additional examples and argumentation, and a consideration of the role of aspect and modality in facilitating suspension).

(52) we have created an industrial framework that provides the average man with comforts and conveniences previously enjoyed by only the most wealthy and pampered, and perhaps, not even by them.

assignments which look very good, assignments which seem to be at a very high level, may actually test knowledge only at the lowest leveland perhaps not even that!

one of their trax samples martin ljung doing his "fingal olsson" routine, which could only make sense to swedes and possibly not even them.

For some reason known only to Microsoft and maybe not even them, using the Orientation constants requires you to be in a different universe

For van Rooij \& Schulz and Ippolito, epistemic cancellation leads to adopting varieties of conversational implicature-based analyses of the relation 
between only sentences and the prejacent, à la McCawley (1981: 311-12): "It is pointless to weaken a universal predication by specifying exceptions if you know that the predication holds of the excepted elements as well." Only Obama can do it scalar-implicates that Obama can do it: if you know that nobody can do it, why assert (merely) that only Obama can? But McCawley's line, however seductive (as this seducee can attest), is fatally incapable of accounting for the distinction between the clearly cancelable true scalar implicatures and the entailed (and thus uncancellable) nature of the prejacent in only sentences and the polar component in almost/barely clauses:

(53) A: Are some dogs mammals?

B: Yes, (some dogs are mammals) and indeed all dogs are mammals.

(54) A: It isn't certain that the economy will recover by 2010.

B: No, it isn't certain — and indeed, it's not even likely.

(55) A: Did only Bush trust Cheney?

$\mathrm{B}_{1}$ : \#Yes, and what's more, even he didn't.

$\mathrm{B}_{2}:{ }^{\%} \mathrm{Y} e s$, and indeed it's possible even he didn't.

(56) A: The economy will barely recover by 2010.

B: Yes, and what's more, \{\#it won't/it might not $\}$ recover even then.

\section{8. not only vs. not...only}

Beaver \& Clark (2008: 227) posit an asymmetry between the suspension of the prejacent of only and that of honest, God-fearing presuppositions, but their examples are misleading. The key condition on presupposition suspension is that such suspension occurs "only in the direction of greater universality, not in the direction of an increased hedge" (Horn 1970: 322-23). Note the parallel in (57), where we see that the prejacent of only can be suspended, but not that of not only.

a. Mary \{\#stopped/didn't stop\} smoking, and maybe she never smoked in the first place.

b. \{Only Mary/\#Not only Mary\} smokes, and maybe even she doesn't.

Given the contrasts in (53)-(56), Beaver \& Clark (2008: 234) are correct in concluding that "prejacent inferences... are too robust to be mere conversational implicatures" à la Ippolito (2006), but I side with the latter against the former in finding the prejacent of not only harder to shed than that of bare only.

What then of the attested cases (Beaver \& Clark 2008: 268-9) where a positive-affirming prejacent of not only is (not just suspended but) cancelled with no epistemic modal in sight?

(58) [Rosalind] Franklin was a spiky personality who not only did not suffer fools gladly but did not suffer them at all. [= B\&C (10.31)] 
CRATYLUS: If we add, or subtract, or misplace a letter, the name which is written is not only written wrongly, but not written at all; and in case of any of these accidents happening, becomes other than a name. [= B\&C (10.30)] [Plato, Cratylus 432A, B. Jowett translation, 1871]

But contra Beaver \& Clark, affirming that Franklin didn't suffer fools at all is not to cancel the negative prejacent that she didn't suffer fools gladly. If someone doesn't speak at SALT at all, they certainly don't speak convincingly: there's no presupposition here, just a readily cancelable implicature. George W. Bush didn't handle the Iraq war successfully, and neither did I. As for (59), if something is written wrongly, it's not just presupposed but entailed that it's written, just as much as if it's written correctly. I didn't handle the Iraq war badly. W did, but not me; I'm off the hook for that one, whatever my other lapses. Thus contrast:

(60) a. The name is not only not written correctly, it is not written at all.

b. \#The name is not only written incorrectly, it is not written at all.

And indeed, all the alternate renderings (e.g. those in Fowler 1926, Barney 2001, and Dominguez 2002) absolve Cratylus from the incoherent claim in (60b). ${ }^{12}$

To be sure, there are speakers who share Jowett's (not Plato's!) tolerance of prejacent-free not only, as when a poster holds that "the case of Allan Menzies was not only managed improperly but was not managed at all" (http://www.scotcourts.gov.uk/opinions/Menzies.html, emphasis added, example due to Brady Clark, p.c.). Still, for most speakers the prejacent implication is more robust for not only than for only, as Ippolito observes. Compare also the outcome of the bets placed in (61) once we learn that the Red Sox have won 103 games and the Yankees 90. While I clearly lose the bet in (61a), the upshot for its counterpart in (61b) is less obvious.

(61) a. I bet you that only the Yankees will win 100 games.

b. I bet you that not only the Yankees will win 100 games.

One key factor in the asymmetry is attributable to the difference between string adjacent not only expressions and canonically negated only. This distinction has often been overlooked, as in the recent conflations of the two configurations by Ippolito (2006: (6)) and Roberts (2006: (11)) echoing Horn (1969: 99), who finds $(62 \mathrm{a}, \mathrm{b})$ to be "mutual paraphrases."

(62) a. Not only Muriel voted for Hubert.

b. It's not true that only Muriel voted for Hubert.

I can only play the A-Rod card: "Back then it was a different culture. I was young, I was stupid."13 I had no idea what I was ingesting-maybe it was

\footnotetext{
${ }^{12}$ The key passage in Cratylus 432A is rendered by Barney (2001: 115) as '... it isn't that we've written the name but incorrectly; rather, we haven't written it at all.'

${ }^{13}$ Alex Rodriguez, quoted 10 February 2010, explaining his use of a banned substance; posted at http://articles.latimes.com/2009/feb/10/sports/sp-a-rod-steroids10.
} 
steroids, maybe it was some other controlled substance, things were pretty loose back then. But now we know better, and in particular that not only $\neq$ not...only. Beaver \& Clark (2008: 235) cite the minimal pair in (63a,b), to which we can add the parallel cases in (64) and (65).

(63) I don't know whether Muriel likes Hubert, but...

a. \#\#Muriel likes not only Hubert.

b. Muriel doesn't like only Hubert.

(64) a. \#Not only Mary did I see smoking - in fact I didn't see anyone smoking.

b. I didn't see only Mary smoking - in fact I didn't see anyone smoking.

(65) a. \#Not only on Sunday does he go to church - he goes only on Friday.

b. He doesn't go to church only on Sunday - he goes only on Friday.

The key generalization is formulated by Seuren (2001: 344-45, following related observations in his earlier work): Presuppositional and analogous material is preserved (and reinforced) under non-canonical negation more robustly than it is with ordinary sentential negation; not only resists suspension of the prejacent in the same way that not every/all reinforces the existential import of the universal.

In any event, however robust the prejacent of constituent not only may be, it is still unasserted; the point of (62a) is to assert that the Hubert voters extend beyond Muriel. This fact is exploited by Sherwood Will in his demonstration that you are an ass, as illustrated in a sophism exploiting the semantically innocent pragmatic asymmetry between the two exponents of not only:

'Only you are an ass' [tu tantum es asinus] is false; therefore 'not only you are an ass' [non tu tantum es asinus] is true; therefore you and someone else are asses.

It must be said that the first [proposition] could be falsified either because you are not an ass or because although you are an ass someone else is an ass too. And the negative "not only you [are an ass]' can be verified for [either of] those two [causes]. Therefore, since only the...second cause of the truth of the negative is inferred from it, there will be a fallacy of the consequent.

(William of Sherwood, Syncategoremata XIV, in O’Donnell 1941: 72, Kretzmann 1968: 95-6)

From the anonymous author of the $12^{\text {th }}$ century Syncategoremata Monacensia (Kretzman \& Stump 1988: 164) who cites 'only' (solus/tantum) to begin his catalogue of "words that afflict the minds of beginners with uncertainty" to von Fintel (1994: 133), who neatly summarizes our central conundrum,

The semantics for only says this: it asserts that no proposition from the set of relevant contrasts $\mathrm{C}$ other than the one expressed by its sister sentence $\alpha$ is true. There is in addition an implicature [sic] that $\alpha$ is in fact true. There is an industry devoted to the issue of whether the latter ingredient is an implicature (conversational or conventional), a presupposition, or part of the truth-conditions. 
semanticists have unpacked the exclusive exponible to discover an unending cornucopia of enlightenment and frustration.

During their forty years of wandering in the wilderness, the Israelites lost their faith and fell to grumbling amidst the hardships of their journey. In despair of reaching the Promised Land, some clamored to return to their Egyptian captivity. So too have many lapsed over the past forty years into confusion, doubt, or the temptation to backslide to the seductive simplicity of the symmetricalist analysis for only and its fellow exponibles. But despair not, rend not your clothes.

We have taken sentences based on only $N P$ - as well as those featuring at most $n C N$, almost $V P$, barely $V P$, and other quasi-conjunctive exponibilia - to entail both conjuncts of the relevant expansion but to assert only one of those conjuncts. Recognizing this asymmetry at the pragmatic level enables us to capture asymmetries reflected inter alia by NPI licensing, negative inversion, scalar orientation, and discourse negativity while avoiding the contradictions incurred by semantically asymmetric accounts. Let the industry thrive!

\section{References}

Abelard, Peter: 1970, Dialectica, 2nd edn., L.M. de Rijk, ed., Van Gorcum, Assen. Amaral, Patricia: 2007, The Meaning of Approximative Adverbs: Evidence from European Portuguese, Doctoral dissertation, The Ohio State University.

Ashworth, E. J.: 1972, 'The Doctrine of Exponibilia in the Fifteenth and Sixteenth Centuries', Vivarium XI, 137-67.

Atlas, Jay D.: 1991, 'Topic/Comment, Presupposition, Logical Form and Focus Stress Implicatures: The Case of Focal Particles only and also', Journal of Semantics 8, 127-47.

Atlas, Jay D.: 1993, "The Importance of Being "Only": Testing the Neo-Gricean Versus Neo-Entailment Paradigms', Journal of Semantics 10, 301-18.

Atlas, Jay D.: 1996, “'Only” Noun Phrases, Pseudo-Negative Generalized Quantifiers, Negative Polarity Items, and Monotonicity. Journal of Semantics 13, 265-332.

Atlas, Jay D.: 1997, 'Negative Adverbials, Prototypical Negation, and the De Morgan Taxonomy', Journal of Semantics 14, 349-68.

Atlas, Jay D.: 2002, 'NPI Licensing and Overcoming Assertoric Inertia. Paper given at One Day Only workshop, Groningen, 8 May 2002, posted at http://staff.science.uva.nl/ p pdekker/Only/Literature/Atlas2.pdf.

Atlas, Jay D.: 2005, Logic, Meaning, and Conversation, Oxford U. Press, Oxford.

Atlas, Jay D.: 2007, 'On a Pragmatic Explanation of Negative Polarity Licensing', in N. Burton-Roberts (ed.), Pragmatics, 10-23, Palgrave, Houndmills.

Barney, Rachel: 2001, Names and Nature in Plato's Cratylus, Routledge, New York.

Beaver, David and Brady Clark: 2003, 'Always and only: Why Not All Focus Sensitive Operators are Alike', Natural Language Semantics 11, 323-62.

Beaver, David and Brady Clark: 2008, Sense and Sensitivity: How Focus Determines Meaning, Wiley-Blackwell, Oxford.

Clark, Brady: 2006, 'Polarity Items and the Interdefinability of Universals and Exclusives', Presented at LSA annual meeting, Albuquerque. 
De Decker, Paul, Erik Larson \& Andrea Martin: 2005, 'Polarity Judgments: An Empirical View', Poster for "Polarity from Different Perspectives", NYU Workshop, March 2005.

Domínguez, Atilano: 2002, Platon: Cratilo o Del lenguaje, Trotta, Madrid.

Ducrot, Oswald: 1972, Dire et ne pas dire, Hermann, Paris.

Ducrot, Oswald: 1973, La preuve et le dire, Maison Mame, Paris.

von Fintel, Kai: 1993, 'Exceptive Constructions', Natural Language Semantics 1, 123-48.

von Fintel, Kai: 1994, Restrictions on Quantifier Domains, Doctoral dissertation, University of Massachusetts.

von Fintel, Kai: 1999, NPI-Licensing, Strawson-Entailment, and ContextDependency, Journal of Semantics 16, 97-148.

Fowler, H. N.: 1926, Cratylus. Loeb Classical Library edition, reprinted by Harvard U. Press, Cambridge, 1977.

Geach, P. T.: 1962, Reference and Generality, Cornell University Press, Ithaca.

Geurts, Bart and Rick Nouwen: 2007, 'At least et al.: The semantics of scalar modifiers', Language 83, 533-59.

Giannakidou, Anastasia: 1998, Polarity Sensitivity as (Non-)Veridical Dependency, John Benjamins, Amsterdam.

Giannakidou, Anastasia: 2006, 'Only, Emotive Factives, and the Dual Nature of Polarity Dependency', Language 82, 575-603.

Hitzeman, Janet: 1992, 'The Selectional Properties and Entailments of "almost", CLS 28, 225-38.

Horn, Laurence: 1969, 'A Presuppositional Analysis of only and even', CLS 5, 97108.

Horn, Laurence: 1970, 'Ain't It Hard (Anymore)', CLS 6, 318-27.

Horn, Laurence: 1972, On the Semantic Properties of Logical Operators in English, Doctoral dissertation, UCLA.

Horn, Laurence: 1979, 'Even, only, and Conventional Implicature', Presentation at annual LSA meeting, Los Angeles.

Horn, Laurence: 1991, 'Given as New: When Redundant Affirmation Isn't', Journal of Pragmatics 15: 313-36.

Horn, Laurence: 1992, 'The Said and the Unsaid', SALT II, 163-92.

Horn, Laurence: 1996, 'Exclusive Company: Only and the Dynamics of Vertical Inference', Journal of Semantics 13, 1-40.

Horn, Laurence: 2002, 'Assertoric Inertia and NPI Licensing', CLS 38-2, 55-82.

Horn, Laurence: 2004, 'Implicature', in L. Horn \& G. Ward (eds.), The Handbook of Pragmatics, 3-28, Blackwell, Oxford.

Ippolito, Michela: 2006, 'The Meaning of only', Unpublished ms., Boston U.

Karttunen, Lauri and Stanley Peters: 1979, 'Conventional Implicature', in C.-K. Oh \& D. Dinneen (eds.), Syntax and Semantics 11: Presupposition, 1-56, Academic Press, New York.

Keenan, Edward and Jonathan Stavi: 1986, 'A Semantic Characterization of Natural Language Determiners', Linguistics and Philosophy 9, 253-326.

Klima, Edward: 1964, 'Negation in English', in J. A. Fodor \& J. J. Katz (eds.), The Structure of Language, 246-323, Prentice-Hall, Englewood Cliffs.

Kretzmann, Norman: 1968, William of Sherwood's Treatise on Syncategorematic Words, U. of Minnesota Press, Minneapolis. 
Kretzmann, Norman and Eleonore Stump: 1988, The Cambridge Translations of Medieval Philosophical Texts, Cambridge University Press, Cambridge.

Lakoff, George: 1970, 'Repartee', Foundations of Language 6, 389-422.

Lewis, Charlton: 1889, Latin Dictionary for Schools, Harper, New York.

Linebarger, Marcia: 1987, 'Negative Polarity and Grammatical Representation', Linguistics and Philosophy 10, 325-87.

McCawley, James D.: 1981, Everything That Linguists Have Always Wanted To Know About Logic, U. of Chicago Press, Chicago.

Mullally, Joseph: 1945, The Summulae Logicales of Peter of Spain, University of Notre Dame, Notre Dame.

Ockham, William of: 1980, Ockham's Theory of Propositions: Part II of the Summa Logicae, University of Notre Dame Press, Notre Dame.

O'Donnell, J. R.: 1941, 'The Syncategoremata of William of Sherwood', Mediceval Studies 3, 46-93.

Peter of Spain: 1972, Tractatus, called afterward Summule Logicales, L. M. de Rijk, ed., Van Gorcum, Assen.

Peter of Spain: 1992, Syncategoreumata, L. M de Rijk, ed.; J. Spruyt, trans. E. J. Brill, Leiden.

Pinborg, Jan: 1981, 'Walter Burley on Exclusives', in H. A. G. Braakhuis et al. (eds.), English Logic and Semantics, 305-26, Ingenium, Nijmegen.

Potts, Christopher: 2005, The Logic of Conventional Implicatures, Oxford U. Press, Oxford.

Rapp, Irene and Arnim von Stechow: 1999, 'Fast "almost" and the Visibility Parameter for Functional Adverbs, Journal of Semantics 16, 149-204.

de Rijk, L. M.: 1985, 'Walther Burley's Tract De exclusivis: An Edition', Vivarium 23, 23-54.

Roberts, Craige: 1996, Information Structure in Discourse: Toward an Integrated Theory of Pragmatics. OSU WPL 49.

Roberts, Craige: 2006, Only, Presupposition, and Implicature. Unpublished ms., The Ohio State University.

van Rooij, Robert and Katrin Schulz: 2007, 'Only: Meaning and Implicature', in M. Aloni et al. (eds.), Questions in Dynamic Semantics, 193-223, Elsevier, London.

Sadock, Jerrold: 1981, 'Almost', in P. Cole (ed.), Radical Pragmatics, 257-71, Academic Press, New York.

Schwenter, Scott: 2002, 'Discourse Context and Polysemy: Spanish casi', in C. Wiltshire \& J. Camps (eds.), Selected Papers from the $30^{\text {th }}$ Linguistic Symposium on Romance Languages, 161-75, John Benjamins, Amsterdam.

Seuren, Pieter: 2001, A View of Language, Oxford U. Press, Oxford.

Sevi, Aldo: 1998, 'A Semantics for almost and barely', M.A. thesis, Tel Aviv U.

Spruyt, Joke: 2008, Peter of Spain. In E. Zalta (ed.), Stanford Encyclopedia of Philosophy, http://plato.stanford.edu/entries/peter-spain/.

Stalnaker, Robert: 1978, 'Assertion', in P. Cole (ed.), Syntax and Semantics 9: Pragmatics, 315-32, Academic Press, New York.

Taglicht, Josef: 1984, Message and Emphasis in English, Longman, London.

van der Wouden, Ton: 1997, Negative Contexts, Routledge, London.

Ziegeler, Debra: 2000, What almost Can Reveal About Counterfactual Inferences, Journal of Pragmatics 32, 1743-76. 
